\title{
Effect of area on color harmony in simulated interiors
}

\section{Seden Odabaşığlu' ${ }^{1}$ ( ) Nilgün Olguntürk ${ }^{2}$ ()}

${ }^{1}$ Department of Interior Architecture, Faculty of Fine Arts, Marmara University, İstanbul, Turkey

${ }^{2}$ Department of Interior Architecture and Environmental Design, Faculty of Art, Design and Architecture, Bilkent

University, Ankara, Turkey

\section{Correspondence}

Seden Odabaşığlu, Department of Interior Architecture, Faculty of Fine Arts, Marmara University, 34660 Kadıköy, İstanbul, Turkey.

Email: sodabasi@bilkent.edu.tr

\begin{abstract}
The main aim of this study is to examine the effect of area on color harmony in simulated interior spaces. The secondary aim of the study is to investigate how the term color harmony is defined and the link between color harmony and related terms used to define it. These terms can explain why a color scheme is evaluated as harmonious. Four sets of three-color combinations created by using the hues red, blue, yellow, green, purple, and orange were studied in a simulated office interior emphasizing different proportional use of each color. Firstly, participants evaluated harmony content of the images. Secondly, they evaluated each image regarding the terms related to color harmony. Findings indicated that area had an effect on color harmony for two of the color combinations (warm \& cool). However, there were no strong but rather moderate and weak correlations between color harmony and the terms.

K E Y W O R D

color harmony, experimental color harmony, simulated interior, three-color combination
\end{abstract}

\section{1 | INTRODUCTION}

Color harmony has been of interest for many researchers for two centuries and has attracted interest in aesthetics from both philosophical and scientific perspectives. By controlling color usage in a design, a designer can distribute the visual weight and achieve balance (one of the aesthetic measures), ${ }^{1,2}$ and thus can achieve aesthetically more pleasing objects or spaces. Many theorists have defined color harmony with the principles they posited based on their experiences to create harmony. These principles were "completeness" for Goethe, ${ }^{3}$ "complementary/analogous" for Chevreul, ${ }^{4}$ "order" for Ostwald ${ }^{5}$, and "balance" for Munsell. ${ }^{6}$ There are also theories based on showing the degree of color harmony with a mathematical formula. Moon and Spencer, in order to explain the relationship between color harmony, color intervals, and area factor, developed a mathematical model. ${ }^{7,8,9}$ According to Moon and Spencer, if there is an ambiguous interval between the colors (difference between colors regarding the attributes of hue, value, and chroma) of a combination, the combination is found unpleasing and therefore is found disharmonious. The studies of Chuang and $\mathrm{Ou},{ }^{10} \mathrm{Ou}$ and $\mathrm{Luo}^{11}$, and $\mathrm{Ou}$ et $\mathrm{al}^{12}$ also followed the theory of indicating color harmony with a formula. These studies developed universal formulas for predicting color harmony; however, they still need to be tested for different conditions and cultures, and they also have some features missing that should be considered, such as area effect and complex environments. Hu et $\mathrm{al}^{13}$ proposed an interactive harmonious color-scheme generator tool based on familial factors and rhythmic spans. This tool should also consider area effect that was also suggested by the evaluators testing it.

There have been a few theories about the influence of area on color harmony, namely, those developed by Munsell and by Moon \& Spencer. ${ }^{14}$ Munsell proposed a rule for areas that the stronger the color the smaller its area must be; while the larger the area, the grayer the chroma. ${ }^{14}$ Moon and Spencer ${ }^{9}$ also claimed that relative area was a function of both value and chroma. Itten ${ }^{15}$ suggested a ratio for harmonious color combinations in one of the seven contrasts he mentioned which is the contrast of extension. However, these ratios indicated the 
inherent lightness of pure colors, and they were valid only when all the hues appeared in their maximum purity. ${ }^{15}$ Moreover, Wang et $\mathrm{al}^{16}$ found that area proportions can be used as weightings in the prediction of harmony and developed a new predictive model adding the areas of the constituent colors to the previous three-color harmony model in which all three attributes of colors took part as weightings (hue, lightness, chroma). This model showed good predictive performance. A recent study was done by Nemcsics and Takacs ${ }^{17}$ investigating the optimum ratio between the area coverage of colors for maximum harmony content of color pairs. The findings of this study showed that area has an influence on the harmony content of color pairs, but it is significant for highly saturated colors and negligible for low-saturated colors.

Studies investigating color harmony in interior spaces ${ }^{12,18,19}$ are also few in number and these studies do not consider the effect of area and the colors are applied only on the walls. However, area in color harmony is an important factor in interior spaces since colors usually are applied in different proportions in interiors on furniture, walls, floor, and ceiling. All these aspects of interiors may be differently colored and accordingly the surface areas and relations of the colors may differ.

Colors in an interior space are dominant elements of design, and it is important to have a harmonious color scheme in an interior space in order to please its users. However, in the studies of color harmony so far, basic patterns have been used for evaluation. Regarding the complexity of the phenomenon, the use of basic patterns in color harmony is a limitation as color patches shown side by side do not fully reflect practical applications, such as in interior spaces where colors have more complex relations than they have in combinations of color patches.

This study mainly aims to examine the effect of area on color harmony in simulated interiors. Additionally, it also aims to investigate how the term color harmony is defined and the link between color harmony and related terms used to define it. The term color harmony is defined differently by different authorities and in experimental studies researchers prefer to use one of these definitions to inform the evaluators. However, it is also important to know how the evaluators define color harmony and according to what they evaluated a color scheme as harmonious. The related terms that are used to define color harmony can explain why a color scheme is evaluated as harmonious.

The hypotheses of the study are as follows:

Hypothesis 1 Color harmony evaluations differ depending on the proportions of constituent colors' areas in interior spaces.
Hypothesis 2 There is a strong and positive relationship between color harmony and the terms (proportion, balance, placement, similarity, lightness, liking, association, naturalness, warmth, relaxation, spaciousness, effect, and pleasantness) used to define it.

Hypothesis 3 There is a strong and positive relationship between all the terms (proportion, balance, placement, similarity, lightness, liking, association, naturalness, warmth, relaxation, spaciousness, effect, and pleasantness) used to define color harmony.

\section{2 | METHOD}

\section{1 | Observers}

Sixty subjects participated in the experiment. The majority of them were university students $(95 \%)$ and $5 \%$ of them were university graduates. The participants had taken no color courses and had no knowledge of color. There were four sets of color combinations (Section 2.4) and different subjects participated in the experiment for each four sets (15 participants for each set). Age ranges of the participants for each set were 18 to 24 (M:20.20 SD:1.656) for set 1, 18 to 29 (M:20.13 SD:2.560) for set 2, 18 to 27 (M:20.20 SD:2.366) for set 3, and 18 to 44 (M:22.13 SD:6.556) for set 4. Gender distributions for each set were 8 females and 7 males for set 1, 5 females and 10 males for set 2, 6 females and 9 males for sets 3 and 4 . All the participants are from Turkey.

\section{2 | Experiment room}

The experiment was conducted in Color Laboratory of Faculty of Technical Education, at Marmara University. The laboratory had no windows and had a viewing condition appropriate for the standard ISO 3664:2009. This standard specifies viewing conditions for images as prints or images displayed on color monitors. The walls and all the furnishing were gray having a Munsell notation of N8. Additionally, the room had fluorescent lamps that simulate Illuminant D50 for illumination.

The monitor used in the experiments for showing the interior images was EIZO ColorEdge CG243W that had a 24 inch wide format LCD and a monitor hood that prevented glare. The monitor was calibrated with i1-Pro2 spectrophotometer that measures detailed spectral information from LCD displays. The obtained values for black level, white point and brightness were $0.15 \mathrm{~cd} / \mathrm{m}^{2}, 5016 \mathrm{~K}$ and $80.2 \mathrm{~cd} / \mathrm{m}^{2}$ respectively which is appropriate for the standard ISO 12646:2008. This data was saved as an 
Intraclass Correlation Coefficient (ICC) color profile to be used in the program that was utilized in the experiments to show the images in a random order. ${ }^{20}$

\subsection{Selecting the function}

The simulated interior space used in the experiment was designated as an office since in these environments furnishings, wall, and floor coverings are kept identical for all users and users are obliged to stay in these spaces. Plan of the office used in the visuals is given in Figure 1.

\section{4 | Specifying the colors}

Three-color combinations, obtained from triads on a 12-color wheel (Itten's color wheel) were used in the experiment. In various sources about color, triads are defined as harmonious color schemes, ${ }^{15,21-24}$ and they are obtained from equilateral or isosceles triangles on a 12-color wheel. There are also modified triads, which are made up of three colors having one color between each on a 12-color wheel such as on Itten's color wheel. ${ }^{25,26}$ Four sets of three-color combinations (triads and modified triads) were created by using the hues (not pure hues) red, blue, yellow, green, purple, and orange. Thus, the selected color schemes were assumed to be harmonious color schemes. The three-color combinations were

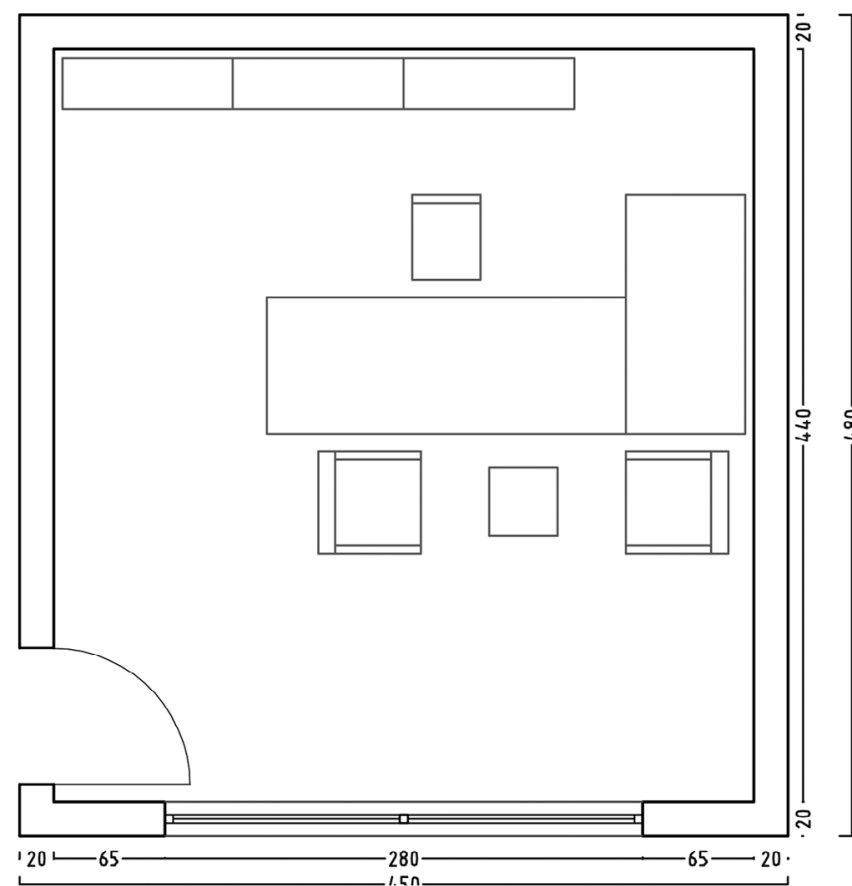

FI G URE 1 Plan of the simulated office applied to walls, table-bookshelf-coffee table, and to seating units (see Figure A1 and Figure A2 in Appendix A for the RGB values of the colors and their application in the office images for all the sets). Floor (R:0.2 G:0.2 B:0.2, L:19.64 a:0.07 b:0.02) and ceiling (R:0.8 G:0.8 B:0.8, L:82.49 a:0.00 b:-0.01) were gray.

The reflectance values of walls, ceiling, floor, and furniture of offices are recommended by Illuminating Engineering Society of North America (IESNA) as 50\% to $70 \%, 80 \%$ or more, $20 \%$ to $40 \%$, and $25 \%$ to $45 \%$, respectively. ${ }^{27}$ Reflectance values of the ceiling, walls and furniture, and floor were adjusted according to these recommendations as $80 \%, 50 \%$, and $20 \%$, respectively. Since the colors that were subject to the harmony evaluations in the experiments were applied to walls and furniture, they had reflectance value of $50 \%$. The highest reflectance recommended by IESNA for furniture was $45 \%$ but it was taken as $50 \%$ in order to make the reflectance values of the colors equal. In order to fix the reflectance levels of the colors, the brightness and saturation levels were fixed in the grayscale and hue differences were searched in these experiments.

\section{5 | Creating the interior space}

RADIANCE ${ }^{28}$ was used to create the interior space for the experiment since this program is a physically based rendering software allowing accurate estimation of the properties of light to produce photometric models. It is important to obtain colors seen physically accurate since in $3 \mathrm{D}$ environments shadows and interreflections have an influence on perception of colors. Ruppertsberg and Bloj ${ }^{29}$ stated that there is not an alternative simulation, which is better than RADIANCE to achieve physical realism.

The selection of a light source for an office depends on color rendering, initial cost, maintenance costs, and energy costs of the light source. ${ }^{27}$ However, it is difficult to recommend a certain color temperature for office spaces because people's preferences for warm and cool light sources differ from individual to individual. ${ }^{27}$ For the selection of the light source, in this study, an important quality to be considered is the color rendering index (CRI) of the light source. IESNA ${ }^{27}$ recommends to choose lamps of $70 \mathrm{CRI}$ or greater in general, or $85 \mathrm{CRI}$ or above if color critical tasks are being performed in an office. Moreover, Dangol et $\mathrm{al}^{30}$ found that in an office environment observers preferred $4000 \mathrm{~K}$. According to these, OSRAM Mira Led (CRI $>85$, CCT 4000) was chosen for the study and the photometry file of this luminaire was used in RADIANCE for rendering. Additionally, IESNA ${ }^{27}$ recommends $500 \mathrm{~lx}$ for horizontal illuminance and $300 \mathrm{~lx}$ for vertical illuminance in a private office. Considering this, 
the horizontal illuminance level that was maintained at the working level was approximately $400 \mathrm{~lx}$.

Related to the areas of the perspective of the office, the proportions of the areas of walls, table-bookshelfcoffee table, and seating units were as 9:3:1, respectively. Accordingly, the proportions of the three-color combinations were 9:3:1. The proportions of the colors and their application in the office images for all the sets can be seen in Figure A1 and Figure A2 in Appendix A.

\section{6 | Preparing the questionnaire}

In a study previously conducted by the authors, the definition of color harmony was asked to 30 participants in order to understand how they determine a color combination to be harmonious. ${ }^{31}$ The participants responded to the questions "What is color harmony according to you? How can a color combination be evaluated as harmonious?" and their answers were analyzed. The words that were used by the participants to describe color harmony, the number of participants using them, and how many times they were repeated are shown in Table 1.

The terms derived from the answers of the participants were transformed into a questionnaire by forming them into word pairs. This questionnaire consisted of 13 word pairs (proportional/not proportional, like/

T A B LE 1 The terms related to color harmony derived from the previously conducted study

\begin{tabular}{|l|llll|}
\hline & $\begin{array}{l}\text { Number of } \\
\text { participants } \\
\text { using } \\
\text { the word }\end{array}$ & \% & $\begin{array}{l}\text { of } \\
\text { the word }\end{array}$ & $\%$ \\
\hline Pleasing & 16 & 19.5 & 16 & 16 \\
\hline Contrast/ & 14 & 17.1 & 15 & 15 \\
\hline analogous & & 12.2 & 15 & 15 \\
\hline Like & 10 & 9.8 & 12 & 12 \\
\hline Balance & 8 & 9.7 & 9 & 9 \\
\hline Tints and shades & 8 & 8.6 & 7 & 7 \\
\hline Warm/cool colors & 7 & 6.1 & 5 & 5 \\
\hline Proportional & 5 & 4.9 & 5 & 5 \\
\hline Spaciousness & 4 & 4.9 & 4 & 4 \\
\hline Calmness & 4 & 2.4 & 6 & 6 \\
\hline Natural colors & 2 & 2.4 & 4 & 4 \\
\hline Association & 2 & 1.2 & 1 & 1 \\
\hline Positive effect & 1 & 1.2 & 1 & 1 \\
\hline Proximity and & 1 & & & \\
\hline distance & & & & \\
\hline
\end{tabular}

dislike, positive association/negative association, natural/ unnatural, warm/cool, relaxed/tense, spacious/cramped, positive effect/negative effect, pleasant/unpleasant, well placed/not well placed, analogous/contrast, light/dark, and balanced/imbalanced) was used in the third phase of the experiment (Section 2.7).

\section{7 | Phases of the experiment}

The experiment was conducted in three phases for all sets. The participants entered the laboratory one by one and the lights were on during the experiments. "The reason for this was that the laboratory had a lighting condition appropriate for the standard ISO 3664:2009 that specifies viewing conditions for images as prints or images displayed on color monitors. The appropriateness of the ambient lighting level to this standard was checked with Eye-One Match program ${ }^{32}$ and it was found to be close to the recommended illuminance level." 20

In the first phase, participants were given Ishihara's Tests for Color-Blindness ${ }^{33}$ and the ones, who passed these tests, participated in other phases of the experiment. Participants who have any eye or vision deficiencies were asked to take the experiment with their correction equipment such as contact lenses or eyeglasses.

In the second phase, each participant was shown the six possible combinations (since the place of the colors were permutated) of the three-color combinations differing in their applied surfaces in a simulated 3D office with a ratio of 9:3:1, which were paired up with each other for the comparison of their color harmony content (Figure 2). In the paired comparison method, participants selected the more harmonious one of the shown two compositions, until they judged each possible composition pair. It was critical to eliminate the possible effect of a definite sequence of seeing the images and the left-right position of the images in each pair. In order to control these effects, a computer program was used for mixing the images randomly. The background of the surface where the paired images were shown to the participants was gray and a blank gray surface was shown for 2 seconds between each evaluation in order to prevent the afterimage effects. This gray surface was also shown before the first comparison.

In the third phase, participants evaluated the six images used in the second phase considering the related terms of color harmony in the questionnaire. They evaluated the images, one by one, by selecting one of the word pairs told to them for indicating which word is more closely associated with the color combination presented. First, the definitions of the words obtained from dictionaries were told to the participants in order to give 


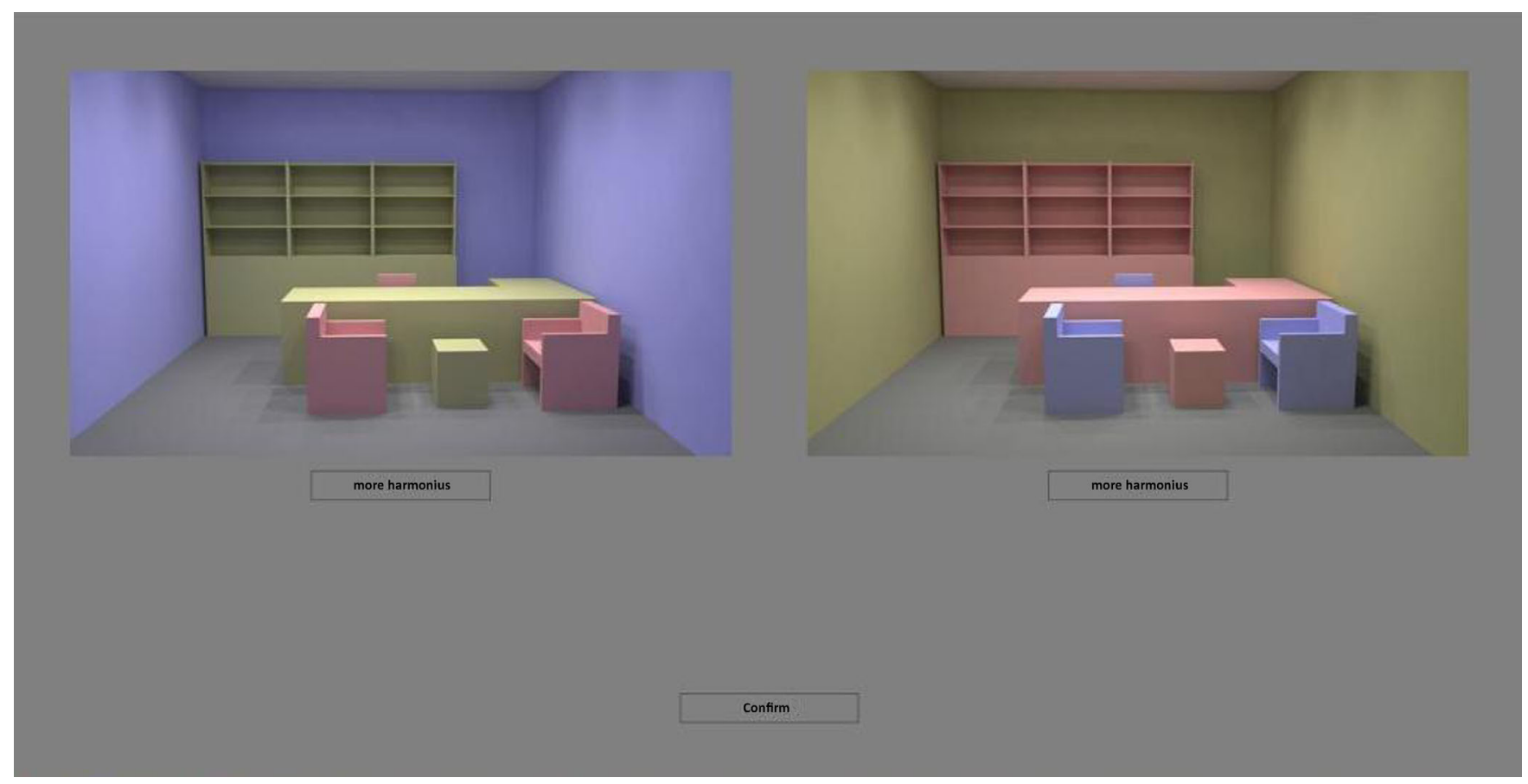

FIG URE 2 One of the paired images that the participants saw while evaluating the harmony content

information about what they assessed (see Appendix B). After this, they answered questions such as "which word is more closely associated with the color combination presented-like or dislike?". The six images were shown randomly to the participants and the word pairs were also asked randomly.

\section{3 | RESULTS AND DISCUSSION}

After all the phases were finished, the collected data were firstly gathered as preference matrices formed by the choices of the participants. The ranks obtained from the matrices were used for consistency, comparison, and correlation analysis.

\section{1 | Consistency analysis}

As mentioned, in the second phase of the experiment participants evaluated the harmony content of the images with the paired comparison method. Although paired comparison is a time-consuming task, it is the most direct and simple task for the observer that has clear and simple goals. ${ }^{34}$ However, there may be inconsistencies, caused by the reluctance of the participants or the difficulty of the experimental task, in the final ranking. Thus, it is important to check the consistency of the evaluations of the observers, before conducting further analysis.
The consistency coefficients were calculated for each participant according to the formula developed by Kendall and Smith. ${ }^{35}$ The evaluations with coefficients of consistency over 0.3 were accepted as consistent and according to this, participants who had unacceptable coefficients were excluded from each set (Table 2). After the exclusion of the inconsistent participants, further analysis of the data was done in SPSS 20.

Inter-rater agreement for the responses to harmony of the colors in the images and to the word pairs was calculated by ICC with absolute agreement. Values of the ICC were classified as poor with an ICC of $<0.5,0.50$ to 0.75 as moderate, 0.75 to 0.90 as good and $>0.90$ as excellent. ${ }^{36}$ Based on the $95 \%$ of confidence interval, ICC values for the harmony of the images were poor for set $2\left(\mathrm{r}_{\mathrm{icc}}=0.48 ;-0.83-0.92\right)$ and they were moderate for set $1\left(r_{\text {icc }}=0.55 ;-0.47-0.93\right)$, set $3\left(r_{\text {icc }}=0.69 ; 0.16-0.95\right)$, and set $4\left(r_{\text {icc }}=0.63 ;-0.18-0.94\right)$. ICC values for the word pairs were moderate for all the sets, set $1\left(\mathrm{r}_{\text {icc }}=0.73\right.$; $0.45-0.90)$, set $2\left(r_{\text {icc }}=0.69 ; 0.36-0.89\right)$, set $3\left(r_{\text {icc }}=0.64\right.$; $-0.04-0.94)$, and set $4\left(\mathrm{r}_{\mathrm{icc}}=0.70 ; 0.39-0.89\right)$.

\section{2 | Comparison analysis}

Following the consistency analysis, a Friedman test was conducted to understand whether or not there were significant differences in harmony depending on the differences in area coverage of the colors in each set. 
According to the Friedman test results, there were no significant differences between the images depending on the differences in the area coverage of the colors in the combination in set 1 (triadic color combination 1-red, blue, yellow) $\left(\mathrm{X}^{2}[5]=7.117, P=.212\right)$ and set 2 (triadic color combination 2-green, purple, orange $)\left(\mathrm{X}^{2}[5]=5.249\right.$, $P=.386)$. Whereas there were significant differences between the images in set 3 (warm color combinationyellow, red, and orange) $\left(\mathrm{X}^{2}[5]=13.291, P=.021\right)$ and set 4 (cool color combination-blue, green, and purple) $\left(\mathrm{X}^{2}[5]=11.508, P=.042\right)$. In order to examine where the differences actually occurred in these two sets (set 3 and 4), post hoc tests were conducted. According to the results, there were significant differences between office

TAB LE 2 Subject consistency values for the second phase of the experiment

\begin{tabular}{lllll} 
Subject & Set 1 & SET 2 & SET 3 & SET 4 \\
1 & 0.625 & 0.125 & 1 & 1 \\
2 & 1 & 0.875 & 0.625 & 0.375 \\
3 & 1 & 0.75 & 0.75 & 1 \\
4 & 1 & 0.375 & 0.5 & 0.75 \\
5 & 1 & 1 & 0.5 & 0.5 \\
6 & 0.25 & 1 & 0.25 & 0.875 \\
7 & 0.75 & 0.875 & 0.75 & 1 \\
8 & 0.75 & 0.25 & 1 & 0.75 \\
9 & 0.75 & 0.125 & 0.375 & 1 \\
10 & 0.5 & 0.625 & 0.875 & 1 \\
11 & 1 & 0.25 & 1 & 1 \\
12 & 1 & 0.875 & 0.125 & 0.875 \\
13 & 1 & 0.5 & 0.75 & 1 \\
14 & 0.75 & 0.875 & 1 & 0.75 \\
15 & 0.75 & 0.25 & 1 & 1 \\
Average & 0.81 & 0.58 & 0.7 & 0.86 \\
\hline
\end{tabular}

5 and office $2(P=.018)$, office 5 and office $3(P=.018)$, office 5 and office $4(P=.005)$, and office 1 and office $4(P=.028)$ in set 3 (see Figure A2 in Appendix A for the images of these offices). In set 4 , there were significant differences between office 1 and office $4(P=.015)$, office 2 and office $4(P=.0008)$, and office 2 and office $5(P=.032)$ (see Figure A2 in Appendix A for the images of these offices).

Considering these differences, when the mean ranks of these images were examined (Figure 3), in set 3 (warm color combination) when orange covered medium area, the color combination was found more harmonious (office 4 and 3). When yellow covered large area, the combination with a medium coverage of orange (office 4) was found more harmonious than the combination with a medium coverage of red (office 5). The color combination with small area coverage of red (office 4) was found more harmonious than the combination with large area coverage of red (office 1). Additionally, in set 3 , when orange covered a medium area, the combinations were found to be the most harmonious (office 4 and 3). When it covered large area (office 2 and 6) the combinations were found to be medium harmonious and when it covered small area (office 1 and 5) the combinations were found to be the least harmonious.

According to the mean ranks of the harmony evaluation of the images in set 4 (cool color combination) (Figure 4), when green covered the least area, the color combination was found to be more harmonious with purple covering a large area (office 2) than the combination with blue covering large area (office 4). The combination with purple covering a large and blue covering a medium area (office 2) was found more harmonious than the combinations in which blue covered the large area (office 5 and 4). Additionally, in set 4, when blue covered a medium area (office 2 and 1), the combinations were found to be the most harmonious. When it covered a small area (office 3 and 6), the combinations were found

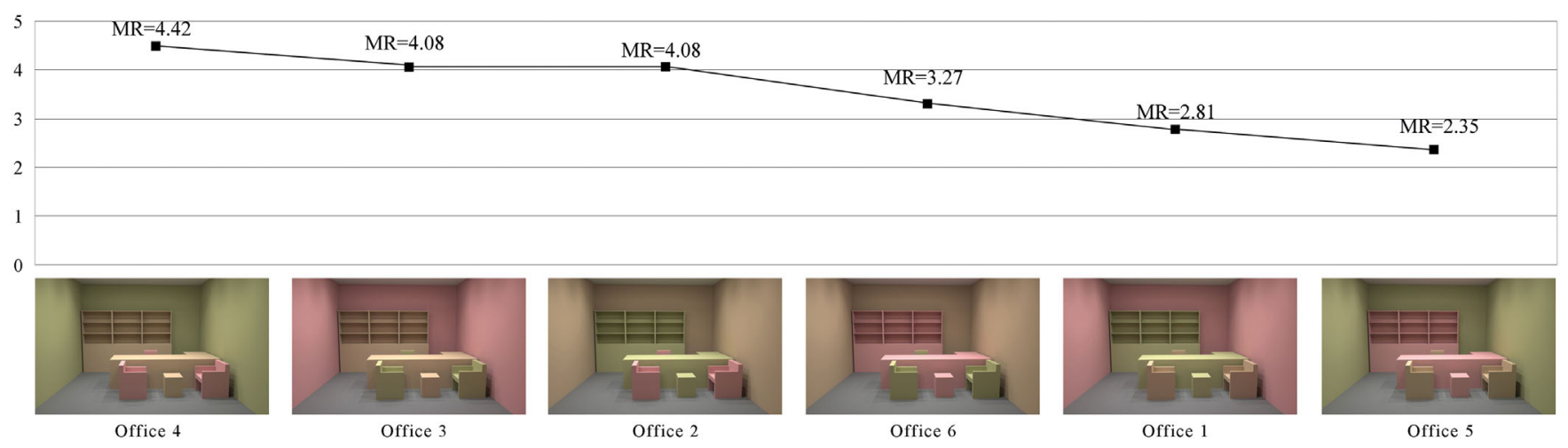

F I G U R E 3 Mean ranks of the images regarding color harmony in set 3 


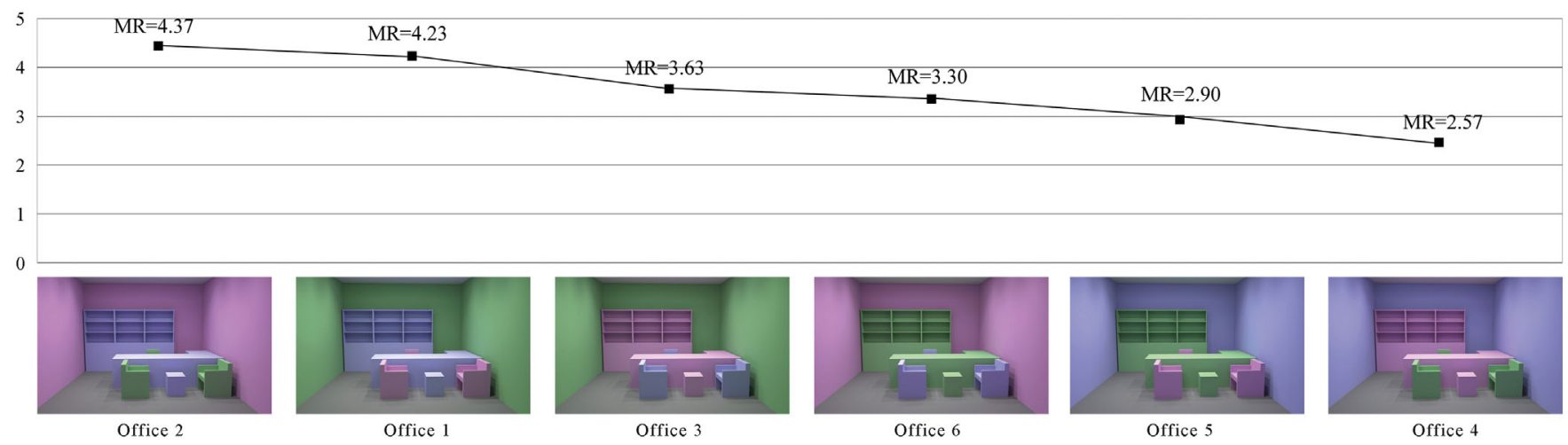

F I G U R E 4 Mean ranks of the images regarding color harmony in set 4

to be medium harmonious and when it covered a large area (office 5 and 4 ) the combinations were found to be the least harmonious.

The findings of this study indicated that, in set 3 (warm color combination), orange was the leading color that influenced the harmony evaluations of the participants. The order of the harmony content of the combinations changed depending on the area covered by orange. The reason for orange being the leading color might be that it is a mixture of red and yellow. Thus, it might work as a mediator in color harmony evaluation of warm color combinations. In some studies, orange was also mentioned as the warmest color among the three. ${ }^{37,38}$ According to this, the findings might be interpreted that color harmony of warm color combinations depend on the area of the color perceived as the warmest.

Moreover, the findings indicated that, in set 4 (cool color combination), blue was the leading color that influenced the harmony evaluations of the participants. The order of the harmony content of the combinations changed depending on the area covered by blue. Different from the warm color combination, in cool color combination, the leading color blue was not the mixture of the other two but it was mixed with other colors (yellow or red) to obtain them in subtractive mixing. It is the base of green and purple. Thus, it might work as a mediator in color harmony evaluation of cool color combination. In literature, blue was also mentioned as the coldest color among the three. ${ }^{38,39}$ According to this, the findings might be interpreted that color harmony of cool color combinations depend on the area of the color perceived as the coldest.

Bonnardel et $\mathrm{al}^{40}{ }^{40}$ in their study searching for the color preferences for a website, found that users and professionals preferred blue and orange the most. Another study, in which preference responses to foregroundbackground color relationships were investigated, also found that blue was the most preferred hue regardless of background color. ${ }^{41}$ Although blue is the most preferred color, in this study, the most harmonious color combinations for cool color scheme were the ones with blue covering medium area. Additionally, although orange was also found to be the most preferred hue, ${ }^{40}$ in this study, the most harmonious color combinations for warm color scheme were the ones with orange covering medium area. This indicates that preference for a single color might not be directly related to color harmony. This is in contradiction with the findings of some studies indicating that the degree of color harmony combinations including preferred colors are higher than the other combinations. ${ }^{10,42}$ However, some studies indicated that there are some cases that harmony and preference may differ. ${ }^{43,44}$

As stated in introduction, there have been a few theories about the influence of area on color harmony. Some of these theories asserted area as a function of value and chroma, ${ }^{6,9}$ some of them proposed a ratio for only pure hues depending on their inherent lightness, ${ }^{15}$ and some of them proposed a formula using all three attributes of colors as weightings (hue, lightness, chroma). ${ }^{16}$ In order to compare the findings of this study with the equations proposed by Munsell ${ }^{6}$ and Moon and Spencer, ${ }^{9}$ RGB values of the selected colors were converted to Munsell Notations. There have been many studies on the topic of conversion between Munsell space and other spaces; ${ }^{45}$ however, there is not a certain conversion model. RGB values were converted to Munsell Notations by using Wallkill Color Munsell Conversion Program Version 12.18.5f (see Figure A1 and Figure A2 in Appendix A for the hue, value and chroma values) and obtained values were used in both of the equations stated above. Calculations showed similar results for both of the equations and indicated an approximate proportion of red:5 blue: 4 yellow: 8 for set 1 , green:5 purple:4 orange:8 for set 2, red:2 yellow:3 orange:3 for set 3 , and blue:4 green:5 purple:4 for set 4 .

Although the ratios used in this study were different from the ones stated above, there are some similarities 
and contradictions considering the findings. According to the equations that Munsell and Moon and Spencer proposed, in set 3 (warm color combination), if red covers less of an area than orange and yellow, the combination is harmonious. Similar to this, findings of this study also indicated that the two combinations with red covering the least area were found to be the first and third most harmonious among the six images. On the other hand, the combination with red covering the largest area was also found to be the second most harmonious in this study indicating that red is not required to cover less area than orange and yellow in a combination for harmony in an interior space.

Moreover, according to the equations that Munsell and Moon and Spencer proposed, in set 4 (cool color combination), if green covers more area than blue and purple, the combination is harmonious. However, the findings of this study indicated that combination with green covering the least and purple covering the largest area was found to be the most harmonious. Supporting the equations, findings also indicated that combinations with green covering the largest area were found to be the second and third most harmonious among the six images.

In order to compare the findings of this study with another theory regarding area effect on color harmony, the three-color combinations used in this study were tested using the three-color harmony model developed by Wang, Ou, and Luo. ${ }^{16}$ Since the model required CIE $L^{*}$, $a^{*}, b^{*}$ values for lightness, chroma, and hue, first, CIE L*, $a^{*}, b^{*}$ measurements were obtained by using Wallkill Color Munsell Conversion Program Version 12.18.5f (see Figure A1 and Figure A2 in Appendix A for the values). According to the model, the obtained values for the images were very close or the same and they had negative values (Table 3) indicating low harmony values with no distinctive difference between the images.

According to the order represented in Table 3, the images had the same harmony values in set 1 and set 2 showing no differences between them. Thus, in primary and secondary triad colors, the area of colors did not affect the harmony content. The findings of this study also supported this. However, although there were differences between the images in set 3 and set 4 , the order of the harmony content of the images were different from the findings of this study.

According to the model proposed by Wang et $\mathrm{al}^{16}{ }^{16}$ in set 3 , the color of the walls led the harmony content of the combination. Color combinations with orange covering a large area were more harmonious than with yellow covering a large area and these were more harmonious than the combinations with red covering a large area. This is in contradiction with the findings of this study, since findings of this study indicated no explicit effect of wall color on harmony content. Besides, combination with yellow covering the largest and orange covering the medium area was found to be the most harmonious.

Furthermore, according to the model, green was the leading color that changed the harmony content of the combinations in set 4 . Color combinations with green covering a small area were more harmonious than with green covering a medium area and these were more harmonious than combinations with green covering a large area. This is also in contradiction with this study, since findings of this study indicated that blue was the leading color that changed the harmony content in set 4 .

Considering the comparisons stated above, the differences between the findings of this study and the theories developed by Munsell and by Moon and Spencer indicated that these theories are questionable in providing an accurate prediction. This supports the findings of the studies ${ }^{14,46-49}$ which examined these two theories and found that none of the theories were acceptable in providing an accurate prediction. Additionally, although the three-color harmony model proposed by Wang et $\mathrm{al}^{16}$ showed good predictive performance, the differences between the findings of this study and the model indicated that it should be tested further with more color combinations.

\section{3 | Correlation analysis}

The items of the questionnaire used in the third phase of the experiment were expected to measure the same property, namely, harmony. Thus, the reliability of the data obtained in the third phase of the experiment was tested using Cronbach's alpha. The coefficient of the 13 items

TA B LE 3 Color harmony values and obtained order of the images according to the model developed by Wang, Ou and Luo (2007)

\begin{tabular}{llllllll} 
& Office 1 & Office 2 & Office 3 & Office 4 & Office 5 & Office 6 & Order of the offices \\
SET 1 & -1.60 & -1.60 & -1.60 & -1.60 & -1.60 & -1.60 & $\mathrm{O} 1=\mathrm{O} 2=\mathrm{O} 3=\mathrm{O} 4=\mathrm{O} 5=\mathrm{O} 6$ \\
SET 2 & -1.59 & -1.59 & -1.59 & -1.59 & -1.59 & -1.59 & $\mathrm{O} 1=\mathrm{O} 2=\mathrm{O} 3=\mathrm{O} 4=\mathrm{O} 5=\mathrm{O} 6$ \\
SET 3 & -1.55 & -1.50 & -1.55 & -1.52 & -1.53 & -1.51 & $\mathrm{O} 2>\mathrm{O} 6>\mathrm{O} 4>\mathrm{O} 5>\mathrm{O} 1=\mathrm{O} 3$ \\
SET 4 & -1.54 & -1.44 & -1.54 & -1.44 & -1.47 & -1.47 & $\mathrm{O} 4=\mathrm{O} 2>\mathrm{O} 5=\mathrm{O} 6>\mathrm{O} 1=\mathrm{O} 3$ \\
\hline
\end{tabular}


was 0.87 . Since the acceptable reliability coefficient is above $0.70^{50}$ the scale was accepted as reliable and was used for further analysis.

First, correlations of the harmony values obtained in the second phase and the values of the terms obtained in the third phase (summed for each image in all the sets) were analyzed to understand the relation between harmony and the terms used to define it. The findings showed that there were positive correlations between harmony and its related terms for 14 of 24 images with a coefficient above 0.2 , which is acceptable (Table 4). Considering the mean harmony ranks of the images, correlations below 0.2 were obtained for the second harmonious image among six images in set 1 ; the first, second, and sixth harmonious images in set 2 , the second and sixth harmonious images in set 3 , and the first, and fourth and sixth harmonious images in set 4 (Table 4).

In order to analyze further the relationship between words and the images, correlations between the harmony content of each image and 13 word pairs were analyzed separately for all the sets. The findings indicated that, in set 1 (triadic color combination 1-red, blue, yellow), harmony was correlated with all the 13 terms with a coefficient above 0.2 for office 1 and office 5. On the other hand, harmony was correlated with only spaciousness for office 4. Additionally, the term spaciousness had a positive correlation with an acceptable coefficient for all the images in set 1 (Table 5). Although there were no significant differences between the harmony content of the images in set 1 , mean ranks indicated that office 5 (yellow covering largest and blue the smallest area), which was correlated with all of the terms, was found the most harmonious among all the images (Table 4). However, although office 4 was not significantly correlated with any of the terms (Table 5), it was the second most harmonious (Table 4).

According to Table 5, in set 2 (triadic color combination 2-green, purple, and orange), correlations with a coefficient above 0.2 were found between harmony and high number of terms for the offices 2 and 3 (nine of the terms) and low number of terms for office 4 (six of the terms). The correlation between office 4 (orange covering largest and green the smallest area) and the terms "liking" and "naturalness" could not be computed by SPSS because the values for that variable are the same across all the participants. All the participants found the color combination of office 4 unnatural and did not like it. Although there were no significant differences between the harmony content of the images in set 2 , mean ranks indicated that office 4 was found the fourth harmonious among the six images (Table 4). Similar to set 1 , the term spaciousness had a positive correlation with an acceptable coefficient for all the images also in set 2 (Table 5). In this set, the term liking can also be accepted as having correlation with harmony for all the images. But this correlation was negative for office 5 . This office that had orange covering the largest area was not liked but found harmonious by the participants.

According to Table 5, in set 3 (warm color combination-yellow, red, and orange), correlations with a coefficient above 0.2 were found between harmony and high number of terms for the offices 4 and 6 (10 of the terms) and low number of terms for office 1 (four of the terms). The harmony of office 4 and office 6 was correlated with more of the terms than the other offices, and they had also the first and third rank in harmony (Table 4). In this set (set 3), different from the previous two, the term relaxation and similarity had a correlation

T A B L E 4 Mean ranks of harmony of the images and the correlations (Spearman) between harmony and its related terms

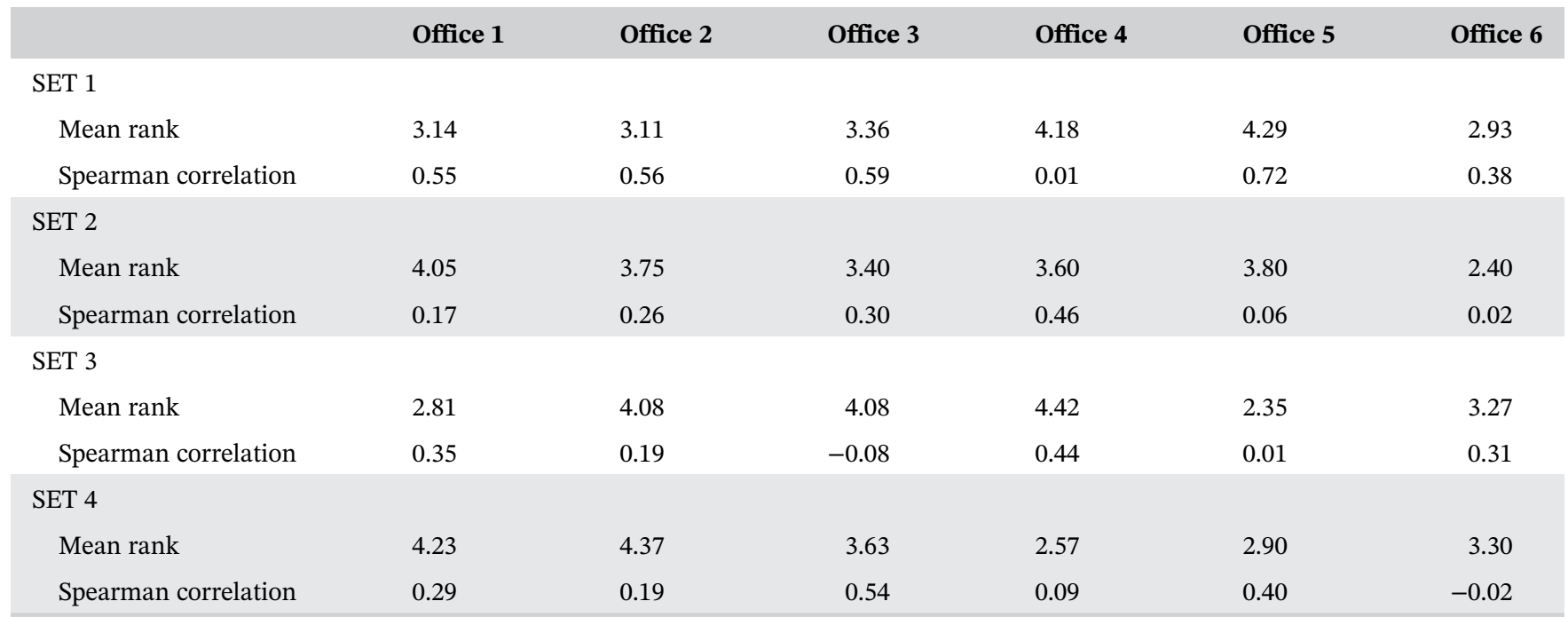




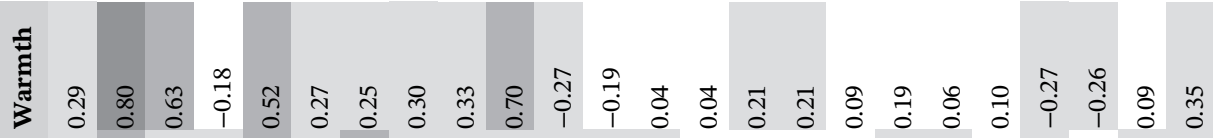
का ๙

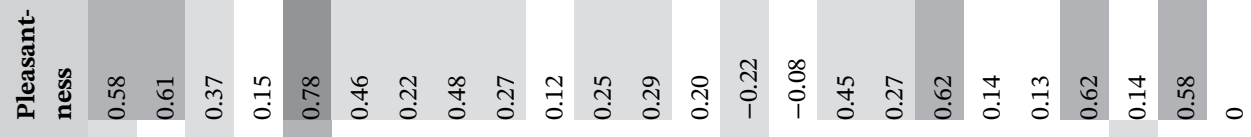

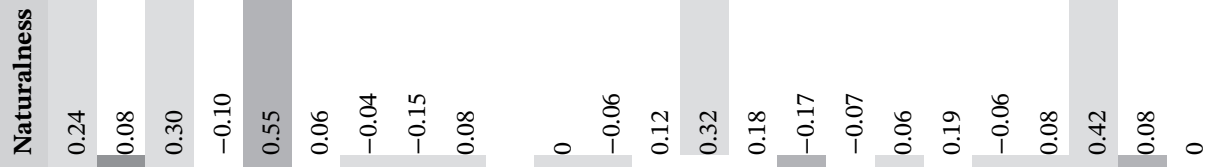

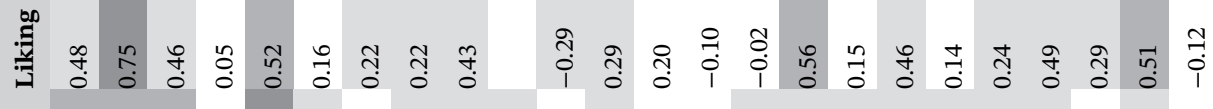

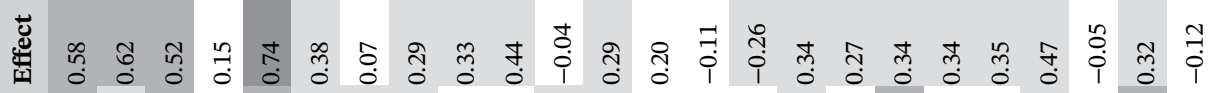

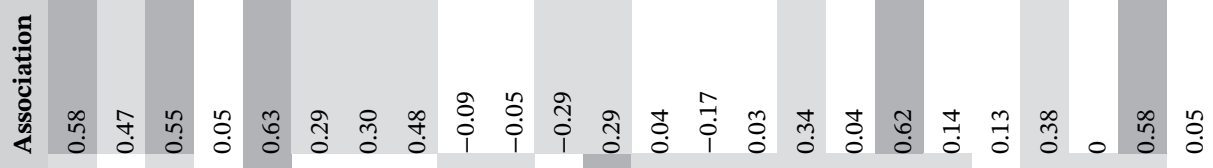

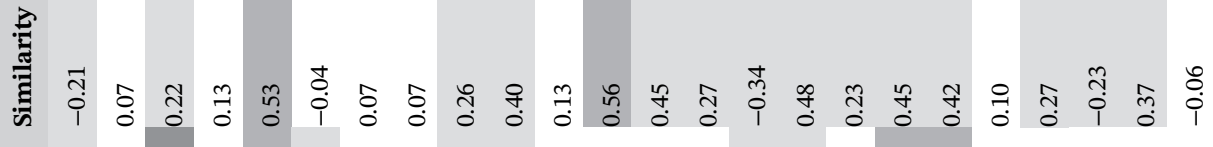

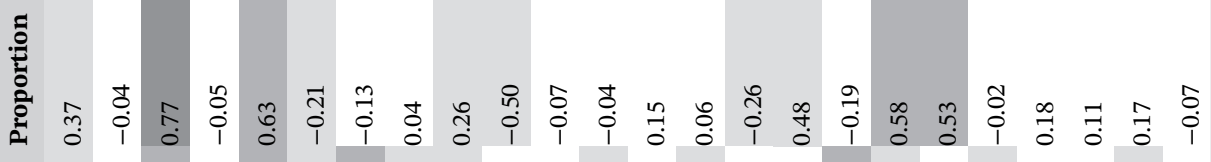
苞 势

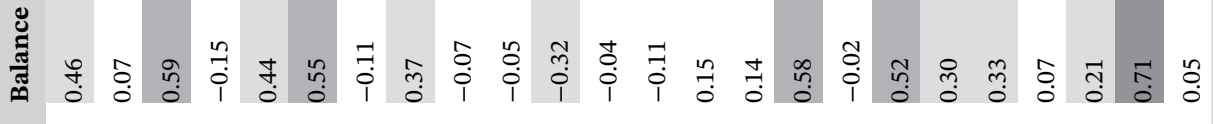

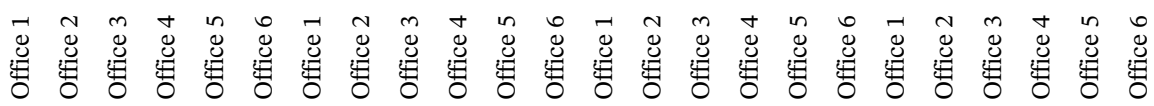
点葶 늘 氙施 竅 


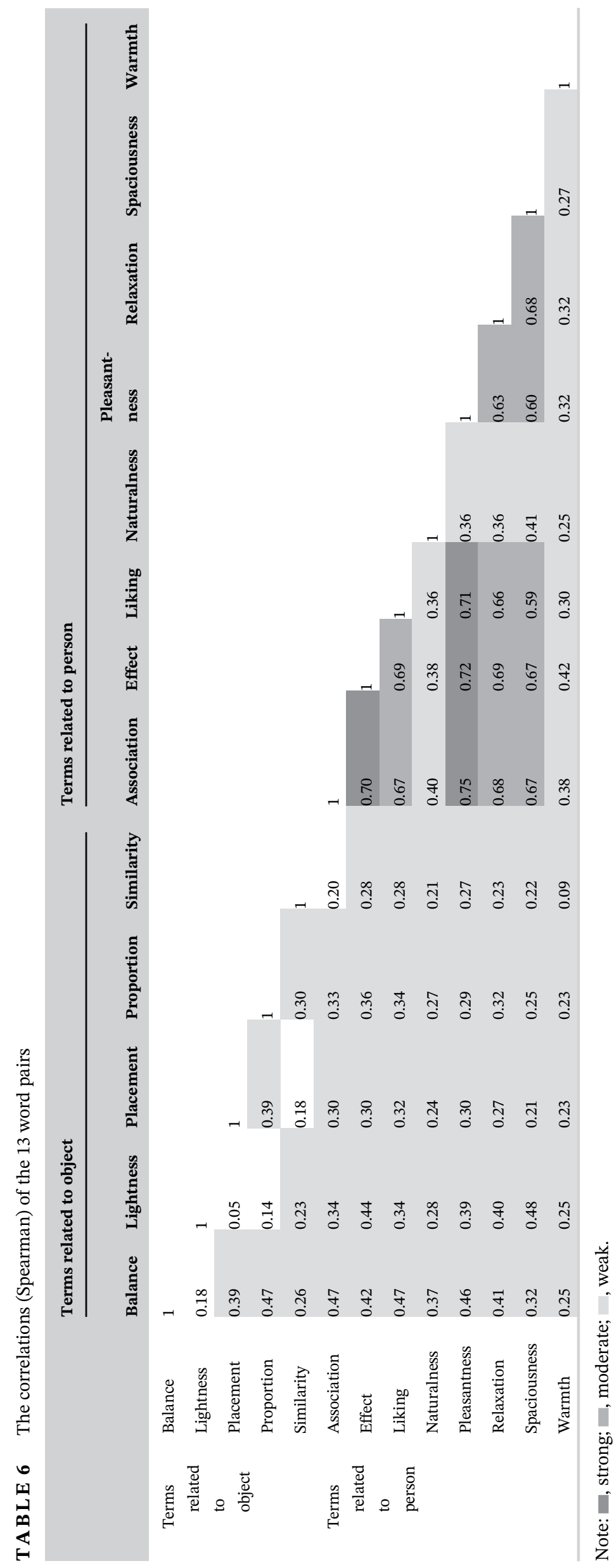


with an acceptable coefficient for all the images (Table 5). These correlations were negative for office 3 in similarity and for office 2 in relaxation. This means that color combination in office 3 that had red covering largest and yellow the smallest area, was found contrasting but harmonious and office 2 that orange covering the largest and red covering the least area was found tense but harmonious.

According to Table 5, in set 4 (cool color combination-blue, green, purple), correlations with a coefficient above 0.2 were found between harmony and high number of terms for office 5 ( 10 of the terms) and low number of terms for office 6 (three of the terms). The harmony of office 5 was correlated with more of the terms than the other offices; however, it had the fifth rank in harmony (Table 4).

It was also hypothesized that there would be a strong link found between the terms defining color harmony. The correlations of the 13 word pairs were shown in Table 6. According to this, the terms that had a strong correlation with each other were association, effect, liking and pleasantness; association and effect. The terms that had a moderate correlation were liking, relaxation, spaciousness, effect and association; spaciousness, effect, pleasantness and relaxation; effect, pleasantness and spaciousness; effect and pleasantness. Correlations between other terms ranged from weak to very weak. The correlation coefficient of the terms proportion, balance and lightness, placement and similarity were below 0.2 and therefore they could be considered to have no correlation. In order to detect other relations between the terms, factor analysis was conducted. A principal component analysis was conducted on the correlations of the 13 terms in order to determine the strength of the correlation of them was reliable for the factor analysis. Since none of the terms was found below 0.30 , they were retained. The variances on the 4 factors were successively extracted with eigenvalues greater than 1 . These four factors accounted for the $74.52 \%$ of the variance as seen in Table 7. Factors and the corresponding loadings of the terms on these four factors are also shown on Table 7. When the extraction was done for two factors, the obtained factors and corresponding loadings of the terms on these two factors are shown in Table 7 in the right column. According to these two factors, the terms were grouped into two as the terms related to object and the terms related to person and were arranged according to this categorization on Table 6. As can be seen from Table 6 , the strong and moderate correlations were not within the terms related to the object but within the terms related to the person.

Although it was expected that there would be a strong link between color harmony and the related terms defining it based on each image, the findings of this study indicated no strong correlation between harmony and the terms, except one of the images shown among all the sets (Table 4). However, moderate, weak, and very weak correlations were found. The reason for this might be the variation of the participants' evaluations causing a decrease in the correlation coefficients.

Considering the findings, it is difficult to say that one term was more correlated with harmony than the other terms for all the sets. This finding was in contradiction with the findings of $\mathrm{Ou}$ et $\mathrm{al}^{43}$ who found that harmony

T A B L E 7 Summary of rotated factors and loadings of the terms

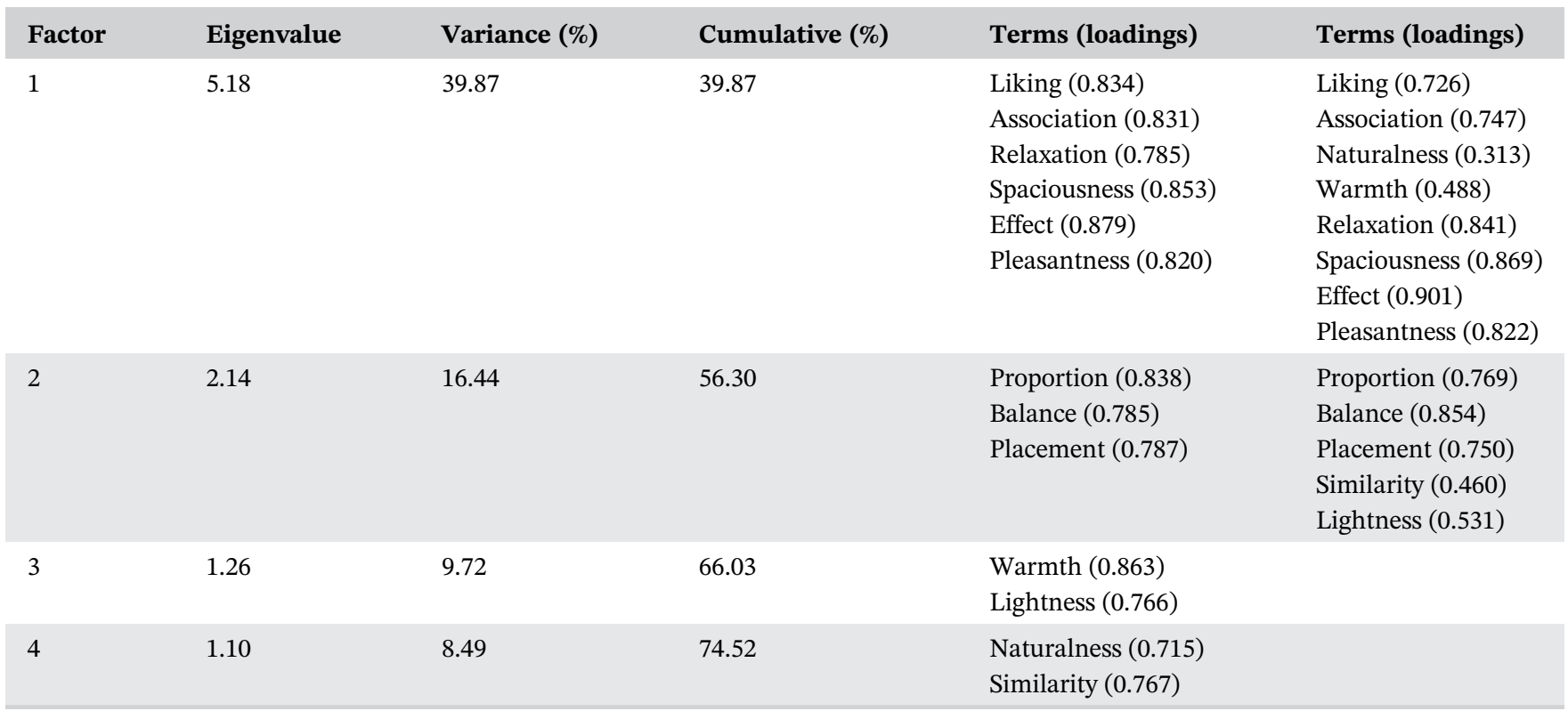


was closely correlated with "liking" (like-dislike) and relaxation (relaxed-tense). However, it also supported the finding of Ou et $\mathrm{al}^{43}$ who found that harmony had a weak correlation with warmth (warm-cool). All of these indicated that the relationship between harmony and the terms related to it needs further investigation in order to be comprehensively explained. There might be some other terms for defining color harmony, which might not be detected with this study but might emerge with further investigations.

Since the obtained terms were assumed to measure the same thing, that is, "harmony," it was expected to find a strong link between the terms used to define color harmony. As stated, strong and moderate correlations (20\% of all the correlations) were found between some of the terms fulfilling partially the expectations. However, many of the terms had weak and very weak correlations ( $80 \%$ of all the correlations). According to the findings (Table 6), participants liked the color combinations, which had positive effects on them and which they found relaxed, spacious, and pleasant associating with positive emotions.

The correlations between all the 13 terms indicated that the significant, strong, and moderate correlations were not within the terms related to object but within the terms related to person. This might mean that participants were more consistent while making evaluations related to themselves than related to the object because it might be difficult to evaluate the properties of an object. The low correlation (coefficient below 0.2) of lightness with proportion, balance, and placement also indicates the difficulty for the participants to evaluate color combinations according to these terms.

\section{4 | CONCLUSION}

In this study, four color schemes were evaluated for their harmony content and the effect of area on harmony was searched.

Hypothesis was partially supported. It was found that color harmony evaluations differed depending on the proportions of the constituent colors' areas for the images in warm and cool color schemes, but not for the images in triadic color schemes.

Various studies regarding color harmony proved that it is universal and there are objective laws for obtaining color combinations, which are found harmonious universally. ${ }^{3-14,16,17,42,51-63}$ The findings of this study also indicate that there is a general pattern of color harmony (which differs depending on the proportions of areas of colors) in interior spaces for some of the color combinations. This finding may also be interpreted as color harmony not being a purely subjective judgment, changing from one person to another. However, various other color combinations, which are accepted as harmonious, should be tested in a further study for testing the weight of area in changing the harmony of them and also for testing whether the findings lead to a different definition of color harmony.

Moreover, in this study, the relationship between color harmony and its related terms was also examined.

Hypothesis was rejected. Since the terms were gathered from the definitions of color harmony obtained from a number of participants, it was expected that these terms and color harmony would have strong correlations. However, it was found that there were no strong but rather moderate and weak correlations between the two.

Hypothesis was partially supported. Regarding the relationship between the terms related to color harmony, it was found that there were significant and strong correlations between some of the terms (pleasantness-liking, association, effect; effect-association) but not all of them and these strong correlations were between the terms related to person.

The implications of the findings of the study can be concluded as follows:

1 The harmonious three-color combinations obtained from equilateral triangles on 12 part color wheel (redblue-yellow and green-purple-orange) are found to be harmonious regardless of area differences.

2 In modified triads (warm and cool color scheme), area differences should be considered while applying these colors to an interior space.

3 Related to the second item, while applying a warm color scheme (red, yellow, and orange) to an interior space, orange should cover the medium area for obtaining the most harmonious combination.

4 Related to the second item again, while applying a cool color scheme (blue, purple and green) to an interior space, blue should cover a medium area for obtaining the most harmonious combination.

This study contributes to the literature as a study of area effect on color harmony in simulated interiors since area effect on color harmony has not been studied in interiors before. The implications of the findings of this study stated above can be used by architects, interior architects/designers, and video game and set designers to obtain pleasant and aesthetic spaces for a wider range of users. The findings of the study also can be used by researchers working on color.

As in all experimental research, this study also has limitations which may lead to future research for exploring more about color harmony in interior spaces. One of 
the limitations of the study is due to color selection. In this study, only 4 three-color combinations (differing in hue) were investigated however in future research the number of combinations can be increased with different hues, chromas, or values. As the number of combinations increases a guideline for harmony with a large number of color combinations can be created for interior designers. Moreover, in this study, area effect on color harmony was investigated in an office. In future research, the same study can be repeated and tested with different kinds of spaces especially public ones such as restaurants, cafes, bars, and schools. Furthermore, in this study gender, age, and cultural differences, which were also found to have an effect on color harmony evaluation in some studies, ${ }^{60,64,65}$ were not investigated. Future research might profit from looking into these other avenues of determining the best forms of creating harmony. Additionally, the effect of material-color associations on color harmony can also be investigated since there might be common material associations for each of the surfaces tested in this study and these associations might cause people to accept certain colors more readily than others for some of the surfaces and might affect harmony evaluations of colors.

\section{ORCID}

\section{Seden Odabaşloğlu (D) https://orcid.org/0000-0003-2794- \\ 803X \\ Nilgün Olguntürk @ https://orcid.org/0000-0001-7947- 1101}

\section{REFERENCES}

[1] Ngo DCL, Teo LS, Byrne JG. Formalising guidelines for the design of screen layouts. Displays. 2000;21(1):3-15.

[2] Ngo DCL. Measuring the aesthetic elements of screen designs. Displays. 2001;22(3):73-78.

[3] Goethe JW. Theory of Colours. Cambridge: M.I.T. Press; 1970.

[4] Chevreul ME. The Principles of Harmony and Contrast of Colors and their Applications to the Arts. West Chester: Schiffer Pub; 1987.

[5] Birren F. The Color Primer: A Basic Treatise on the Color System of Wilhelm Ostwald. New York: Van Nostrand Reinhold; 1969.

[6] Birren F. A Grammar of Color: A Basic Treatise on the Color System of Albert H. Munsell. New York: Van Nostrand Reinhold; 1969.

[7] Moon P, Spencer DE. Aesthetic measure applied to color harmony. J Opt Soc Am. 1944;34(4):234-242.

[8] Moon P, Spencer DE. Geometric formulation of classical color harmony. J Opt Soc Am. 1944;34(1):46-59.

[9] Moon P, Spencer DE. Area in color harmony. J Opt Soc Am. 1944;34(2):93-103.

[10] Chuang M, Ou L. Influence of a holistic color interval on color harmony. Color Res Appl. 2001;26(1):29-39.
[11] Ou LC, Luo MR. A color harmony model for two-color combinations. Color Res Appl. 2006;31(3):191-204.

[12] Ou LC, Chong P, Luo MR, Minchew C. Additivity of color harmony. Color Res Appl. 2011;36(5):355-372.

[13] Hu G, Pan Z, Zhang M, Chen D, Yang W, Chen J. An interactive method for generating harmonious color schemes. Color Res Appl. 2014;39(1):70-78.

[14] Granger GW. Area balance in color harmony: an experimental study. Science. 1953;117(3029):59-61.

[15] Birren F. The Elements of Color: A Treatise on the Color System of Johannes Itten, Based on His Book the Art of Color. New York: Van Nostrand Reinhold; 1970.

[16] Wang X, Ou LC, Luo MR. Influence of area proportion on color harmony. Paper presented at International Conference on Colour Harmony: Proceedings; April 24-26, 2007; Budapest, Hungary.

[17] Nemcsics A, Takacs J. Experimental determination of laws of color harmony. Part 8: harmony content versus relative surface coverage. Color Res Appl. 2014;39(4):387-398.

[18] Shen YC, Chen YC, Hsu WH. Quantitative evaluation of color harmony via linguistic-based image scale for interior design. Color Res Appl. 1996;21(5):353-374.

[19] Shen YC, Yuan WH, Hsu WH, Chen YS. Color selection in the consideration of color harmony in interior design. Color Res Appl. 2000;25(1):20-31.

[20] Odabaşıoğlu S, Olguntürk N. Effect of area on color harmony in simulated interiors, In: Proceedings of $25^{\text {th }}$ Color Imaging Conference; 2017; 258-263.

[21] Burchett KE. Color harmony attributes. Color Res Appl. 1991; 16(4):275-278.

[22] Portillo M. Color Planning for Interiors: an Integrated Approach to Color in Designed Spaces. Hoboken: John Wiley \& Sons; 2009.

[23] Westland S, Laycock K, Cheung V, Henry P, Mahyar F. Colour harmony. Color Des Creativity. 2007;1(1):1-15.

[24] Pile J. Color in Interior Design. New York: McGraw-Hill; 1997.

[25] Leland N. Exploring Color: How to Use and Control Color in Your Painting. Cincinnati: North Light Publishers; 1998.

[26] Leland N. Confident Color: An Artist's Guide to Harmony, Contrast and Unity. Cincinnati: North Light Publishers; 2008.

[27] IESNA. IESNA Lighting Handbook: Reference and Application. New York: Illuminating Engineering Society of North America; 2000.

[28] RADIANCE [Computer Software]. http://radsite.lbl.gov/ radiance/. Accessed January 10, 2012.

[29] Ruppertsberg AJ, Bloj M. Rendering complex scenes for psychophysics using RADIANCE: how accurate can you get? J Opt Soc Am. 2006;23(4):759-768.

[30] Dangol R, Islam MS, Hyvarinen M, Bhushal P, Puolakka M, Halonen L. User acceptance stu9dies for LED office lighting: preference, naturalness and colourfulness. Lighting Res Technol. 2015;47(1):36-53.

[31] Odabaşıoğlu S. Effect of Area on Color Harmony in Interior Spaces [Unpublished Doctoral dissertation]. Ankara: Bilkent University; 2015.

[32] Xrite. i1match [Computer software]. https://www.xrite.com/ i1match. Accessed April 10, 2014.

[33] Ishihara S. Ishihara's Tests for Colour-Blindness. Japan: Kanehara Medical Publishing Co. Ltd.; 1975. 
[34] Livens S, Anthonis A, Mahy M, Scheunders P. A cross media tonal mapping obtained from psychometric experiments. Paper presented at SPIE 5008 Color Imaging, DeviceIndependent Color, Color Hardcopy and Graphic Arts VII: Proceedings; January 20, 2003; Santa Clara, CA, USA: 14-23.

[35] Kendall MG, Smith BB. On the method of paired comparisons. Biometrika. 1940;31(3-4):324-345.

[36] Koo TK, Li MY. A guideline of selecting and reporting Intraclass correlation coefficients for reliability research. J Chiropr Med. 2016;15(2):155-163.

[37] Colombo C, Bimbo AD, Pala P. Retrieval of commercials by video semantics. Paper presented at IEEE Computer Society Conference on Computer Vision and Pattern Recognition: Proceedings; June 23-25, 1998; Santa Barbara, CA, USA: 572-577.

[38] Hardin CL. Explaining basic color categories. Cross Cult Res. 2005;39(1):72-87.

[39] Oyama T, Nanri R. The effects of hue and brightness on the size of perception. Jpn Psychol Res. 1960;2(1):13-20.

[40] Bonnardel N, Piolat A, Bigot LL. The impact of color on website appeal and users' cognitive processes. Displays. 2011; 32(2):69-80.

[41] Camgöz N, Yener C, Güvenç D. Effects of hue, saturation, and brightness on preference. Color Res Appl. 2002;27(3): 199-207.

[42] Nemcsics A. Experimental determination of laws of color harmony. Part 4: color preference and the color harmony content. Color Res Appl. 2009;34(3):210-224.

[43] Ou LC, Luo MR, Woodcock A, Wright A. A study of color emotion and color preference. Part III: color preference modeling. Color Res Appl. 2004;29(5):382-389.

[44] Ou LC, Luo MR, Woodcock A, Wright A. A study of color emotion and color preference. Part II: color emotions for twocolor combinations. Color Res Appl. 2004;29(4):292-298.

[45] Mahyar F, Cheung V, Westland S. Different transformation methods between CIELAB coordinates and Munsell hue. Color Technol. 2010;126(1):31-36.

[46] Linnett CM, Morriss RH, Dunlap WP, Fritchie CJ. Differences in color balance depending upon mode of comparison. J Gen Psychol. 1991;118(3):271-283.

[47] Morriss RH, Dunlap WP, Hammond SE. Influence of chroma on spatial balance of complementary hues. Am J Psychol. 1982;95(2):323-332.

[48] Morriss RH, Dunlap WP. Influence of value on spatial balance of color pairs. J Gen Psychol. 1987;114(4):353-361.

[49] Morriss RH, Dunlap WP. Joint effects of chroma and value on spatial balance of color pairs. Empir Stud Arts. 1988;6(2): 117-126.

[50] Hidayetoğlu ML, Yıldırım K, Akalın A. The effects of color and light on indoor wayfinding and the evaluation of the perceived environment. J Environ Psychol. 2012;32(1):50-58.

[51] Itten J. The Art of Color: The Subjective Experience and Objective Rationale of Color. New York: Van Nostrand Reinhold; 1973.

[52] Nemcsics A. Experimental determination of laws of color harmony. Part 1: harmony content of different scales with similar hue. Color Res Appl. 2007;32(6):477-488.

[53] Nemcsics A. Experimental determination of laws of color harmony. Part 2: harmony content of different monochrome color pairs. Color Res Appl. 2008;33(4):262-270.
[54] Nemcsics A. Experimental determination of laws of color harmony. Part 3: harmony content of different hue pairs. Color Res Appl. 2009;34(1):33-44.

[55] Nemcsics A. Experimental determination of laws of color harmony. Part 5: the harmony content of the various hue triads. Color Res Appl. 2011;36(2):127-139.

[56] Nemcsics A. Experimental determination of laws of color harmony. Part 6: numerical index system of color harmony. Color Res Appl. 2012;37(5):343-358.

[57] Nemcsics A, Takacs J. Experimental determination of laws of color harmony. Part 7: experiments carried out with eyes adapted to light and dark. Color Res Appl. 2013;38(6):448-455.

[58] Nemcsics A, Takacs J. Preference and harmony of neutral colors in 50-year apart. Color Res Appl. 2019;44(1):98-105.

[59] Ou LC, Luo MR. Factors affecting color harmony for two-color combinations. Paper presented at AIC: Proceedings; August 4-6, 2003; Bangkok, Thailand: 379-382.

[60] Ou LC, Luo MR, Sun PL, Hu NC, Chen HS. Age effects on color emotion, preference and harmony. Color Res Appl. 2011; 37(2):92-105.

[61] Polzella DJ, Montgomery DA. Dimensions of color harmony. Bull Psychon Soc. 1993;31(5):423-425.

[62] Szabo F, Bodrogi P, Schanda J. Experimental modeling of color harmony. Color Res Appl. 2010;35(1):34-39.

[63] Lara-Alvarez C, Reyes T. A geometric approach to harmonic color palette design. Color Res Appl. 2019;44(1):106-114.

[64] Huang M, Cui G, Melgosa M, et al. Color harmony in twopiece garments. Color Res Appl. 2017;42(4):498-511.

[65] Ou LC, Yuan Y, Sato T, et al. Universal models of color emotion and color harmony. Color Res Appl. 2018;43(5):736-748.

\section{AUTHOR BIOGRAPHIES}

Seden Odabaşığlu received a B.Arch., MA, and $\mathrm{PhD}$ degrees in interior architecture from Bilkent University, Turkey. She is a research assistant in the Department of Interior Architecture at Marmara University, İstanbul. She has research and experience on space perception, color harmony, and color and lighting design in interiors. Her teaching includes basic design, interior design, design theory, and color and lighting.

Nilgün Olguntürk is an associate professor in the Department of Interior Architecture and Environmental Design, the Faculty of Art, Design, and Architecture, Bilkent University, Ankara. She received a B. Arch., MA, and PhD degrees in architecture. Her professional experience has included appointments as an instructor at the Middle East Technical University and research fellow at the London South Bank University. She has worked on research projects in the UK for NHS Estates (Department of Health) on color design in hospitals and EPSRC/DTLR LINK 
(Department of Transport, Local Government, and the Regions) on color, visual impairment, and transport environments. She has 20 years of research and experience on color perception, color preference, and color use in architecture. Her current research and teaching include color and lighting in undergraduate and graduate studios. She is among others, an active member in the CIE (International Commission of Illumination), the AIC (International Colour Association), the ISCC (Inter-Society Color Council), and the UIA (Chamber of Architects of Turkey).

How to cite this article: Odabaşığlu S, Olguntürk N. Effect of area on color harmony in simulated interiors. Color Res Appl. 2020;45:

710-727. https://doi.org/10.1002/col.22508

\section{APPENDIX}

\section{Description of the words in Turkish}

“Orantılı/Orantısız: Orantı "bir şeyi oluşturan parçaların kendi aralarında ve parçalarla bütün arasında bulunan uygunluk, oran” (TDK Büyük Türkçe Sözlük, t.y.) anlamına gelmektedir. Parçaların kendi aralarında ve parçalarla bütün arasındaki bu ilişki miktar veya boyut açısından olabilir. Bu çalışmada, kullanılan renklerin orantılı olup olmadıkları uygulandıkları yüzeylerin boyutlarıyla ilişkili olarak değerlendirilmektedir.

"Beğendim/Beğenmedim: Beğenmek bir şeyi "iyi veya güzel bulmak” (TDK Büyük Türkçe Sözlük, t.y.) anlamina gelmektedir.

"Olumlu/Olumsuz çă̆rışım: Çağrışım, zihinde, farklı şeyler (düşünce, kavram, vb.) arasında kurulan bağlantıdır. $\quad \mathrm{Bu}$ çalışmada, kullanılan renk kombinasyonlarının neden olduğu duygusal çağrışımlar göz önünde bulundurulmaktadır.”

"Doğal/Yapay: Doğal "doğanın kendi düzeni içinde oluşan, yapay olarak hazırlanmamış olan” (TDK Büyük Türkçe Sözlük, t.y.) anlamına gelmektedir. Yapay ise insanlar tarafından yapılmış anlamındadır.

"Sicak/Soğuk: Sicak renkler insana canlılık ve sicaklık hissi veren renklerdir. Soğuk renkler ise insana sakinlik ve serinlik hissi veren renklerdir."

"Sakinleștirici/Gerginleștirici: Sakin "durgun, dingin” (TDK Büyük Türkçe Sözlük, t.y.), rahat olmak, gergin ise "huzursuz” (TDK Büyük Türkçe Sözlük, t.y.), endişeli ve rahatsız olmak anlamina gelmektedir."
"Ferah/Boğucu: Ferah "bol, geniş, havadar, aydınlı"” (TDK Büyük Türkçe Sözlük, t.y.) anlamına, boğucu ise dar ve sıkıntılı anlamına gelmektedir."

"Olumlu/Olumsuz etki: Bu kelime çifti, uygulanan renk kombinasyonlarının bıraktığı etkiyi değerlendirmek içindir."

"Hoş/Hoş değil: Hoş "beğenilen" (TDK Büyük Türkçe Sözlük, t.y.), çekici bulunan anlamına gelmektedir."

"Iyi yerleștirilmiş/İyi yerleștirilmemiş: Bu kelime çifti, renklerin düzenlenişlerini (ofis mekanı içerisinde doğru yerde konumlanıp konumlanmadıklarını) değerlendirmek içindir."

"Benzer/Zıt: Zit, "nitelikleri ve durumları birbirine büsbütün aykırı olan” (TDK Büyük Türkçe Sözlük, t.y.), benzer ise "nitelik, görünüş ve yapı bakımından bir başkasına benzeyen veya ona eş olan" (TDK Büyük Türkçe Sözlük, t.y.) anlamına gelmektedir.”

“Açı/Koyu: Açık "rengi koyu olmayan” (TDK Büyük Türkçe Sözlük, t.y.), koyu ise "rengi açık olmayan" (TDK Büyük Türkçe Sözlük, t.y.) anlamına gelmektedir.”

"Dengeli/Dengeli değil: Denge, zit güçlerin ya da etkilerin eşit ya da doğru miktarlarda olması durumudur."31

\section{Description of the words in English}

"Proportional \& Not proportional: Proportion means "the relationship of one thing to another in terms of quantity, size, or number; ratio" (Oxford Dictionary, n.d.)."

"Like \& Dislike: Like means to "enjoy something or think that it is nice or good" (Longman dictionary of contemporary English, n.d.)."

"Positive/negative association: Association means a "connection made in the mind between different things, ideas, etc." (Longman dictionary of contemporary English, 1991, p.55). For this study, emotional associations were considered.

"Natural \& Unnatural: Natural means "existing in nature and not caused, made, or controlled by people" (Longman dictionary of contemporary English, n.d.)."

"Warm \& Cool: Warm means "giving a pleasant feeling of cheerfulness or friendliness" (Longman dictionary of contemporary English, 1991, p.1186) and a warm color is one that is based on or contains a color such as red, yellow or orange that suggests warmth (Cambridge Dictionaries Online, n.d.). Cool "describes colors, such as blue or green, that make you feel calm and relaxed" (Cambridge Dictionaries Online, n.d.)."

"Relaxed \& Tense: Relaxed means "feeling calm, comfortable and not worried or annoyed" (Longman dictionary of contemporary English, n.d.). Tense means "feeling worried, uncomfortable, and unable to relax" (Longman dictionary of contemporary English, n.d.).” 
"Spacious \& Cramped: Spacious means "large and with a lot of space" (Cambridge Dictionaries Online, n.d.). Cramped means "uncomfortably small or restricted" (Oxford Dictionary, n.d.). This adjective pair is for evaluating whether or not the applied color combinations cause a feeling of spaciousness for the office environment."

"Positive/negative effect: This is for evaluating whether or not the applied color combinations influence the subjects positively ["if you are positive about things, you are hopeful and confident, and think about what is good in a situation rather than what is bad" (Longman dictionary of contemporary English, n.d.)] or negatively ["considering only the bad qualities of a situation, person, etc. and not the good ones" (Longman dictionary of contemporary English, n.d.)].”

"Pleasant \& Unpleasant: Pleasant means "enjoyable or attractive and making you feel happy" (Longman dictionary of contemporary English, n.d.).”
"Well/not well placed: Placement means "the act of finding the right place for something" (Cambridge Dictionaries Online, n.d.). This word pair is for evaluating the configuration of the colors, whether or not they are applied to the right places in the office environment."

"Analogous \& contrast: Contrast means a difference between people or things that are compared" (Longman dictionary of contemporary English, 1991, p.223). Analogous means "similar or alike in some ways; able to be compared (with) (Longman dictionaryofcontemporaryEnglish,1991,p.30)."

"Light \& dark: "A light color is pale and not dark" and a dark color is "quite close to black in color" (Longman dictionary of contemporary English, n.d.)."

"Balanced \& imbalanced: Balance means "a state in which opposite forces or influences exist in equal or the correct amounts, in a way that is good" (Longman dictionary of contemporary English, n.d.)." 31

\begin{tabular}{|c|c|c|c|c|c|c|c|}
\hline 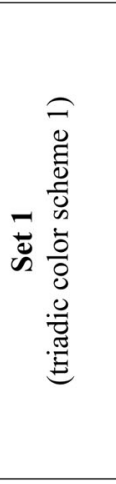 & 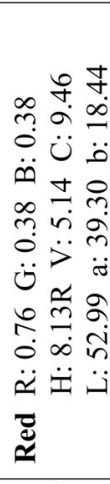 & 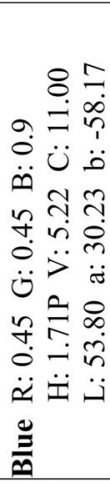 & 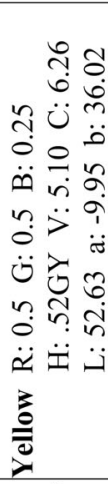 & 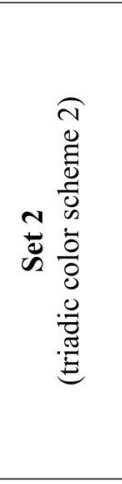 & 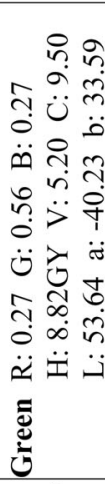 & 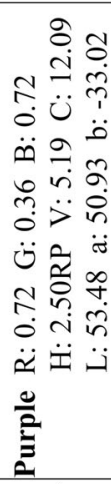 & 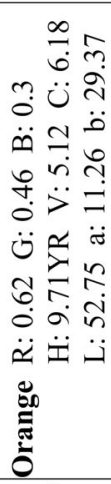 \\
\hline \multirow[b]{2}{*}{ Office 1} & 9 & 1 & 3 & \multirow[b]{2}{*}{ Office 1} & 9 & 1 & 3 \\
\hline & & & & & & & \\
\hline \multirow[b]{2}{*}{ Office 2} & 1 & 9 & 3 & \multirow[b]{2}{*}{ Office 2} & 1 & 9 & 3 \\
\hline & & & & & & & \\
\hline \multirow[b]{2}{*}{ Office 3} & 9 & 3 & 1 & \multirow[b]{2}{*}{ Office 3} & 9 & 3 & 1 \\
\hline & & 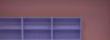 & & & & & \\
\hline \multirow[b]{2}{*}{ Office 4} & 1 & 3 & 9 & \multirow[b]{2}{*}{ Office 4} & 1 & 3 & 9 \\
\hline & & $=$ & & & & $1=$ & \\
\hline \multirow[b]{2}{*}{ Office 5} & 3 & 1 & 9 & \multirow[b]{2}{*}{ Office 5} & 3 & 1 & 9 \\
\hline & & & & & & $7=$ & \\
\hline \multirow[b]{2}{*}{ Office 6} & 3 & 9 & 1 & \multirow[b]{2}{*}{ Office 6} & 3 & 9 & 1 \\
\hline & & $=$ & & & & $A=$ & \\
\hline
\end{tabular}

FI G U RE A1 RGB, HVC and Lab values and proportions of the colors (set $1 \& 2)$ 
F I G U RE A2 RGB, HVC and Lab values and proportions of the colors (set $3 \& 4$ )

\begin{tabular}{|c|c|c|c|c|c|c|c|}
\hline 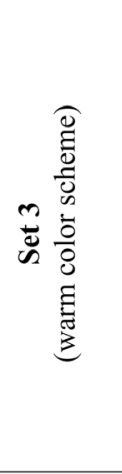 & 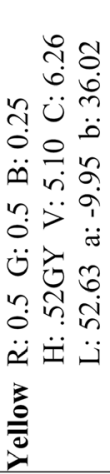 & 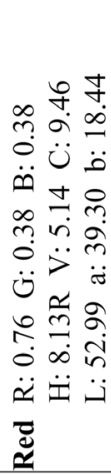 & 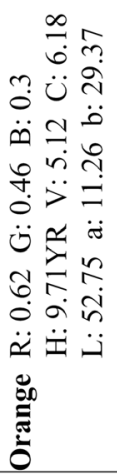 & 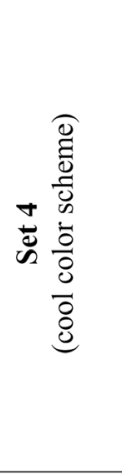 & 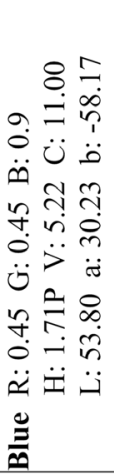 & 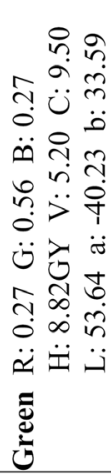 & 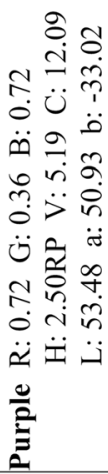 \\
\hline \multirow[b]{2}{*}{ Office 1} & 3 & 9 & 1 & \multirow[b]{2}{*}{ Office 1} & 3 & 9 & 1 \\
\hline & & & & & & & \\
\hline \multirow[b]{2}{*}{ Office 2} & 3 & 1 & 9 & \multirow[b]{2}{*}{ Office 2} & 3 & 1 & 9 \\
\hline & & & & & & & \\
\hline \multirow[b]{2}{*}{ Office 3} & 1 & 9 & 3 & \multirow[b]{2}{*}{ Office 3} & 1 & 9 & 3 \\
\hline & & 是是 & & & & & \\
\hline \multirow[b]{2}{*}{ Office 4} & 9 & 1 & 3 & \multirow[b]{2}{*}{ Office 4} & 9 & 1 & 3 \\
\hline & & & & & & & \\
\hline \multirow[b]{2}{*}{ Office 5} & 9 & 3 & 1 & \multirow[b]{2}{*}{ Office 5} & 9 & 3 & 1 \\
\hline & & & & & & 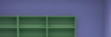 & \\
\hline \multirow[b]{2}{*}{ Office 6} & 1 & 3 & 9 & \multirow[b]{2}{*}{ Office 6} & 1 & 3 & 9 \\
\hline & & & & & & & \\
\hline
\end{tabular}

